\title{
Energy efficiency optimization of ore grinding by ball mills in a closed cycle with a single-spiral classifier
}

https://doi.org/10.31713/MCIT.2020.19

\author{
Anatolii Matsui \\ Department of Automation of Production Processes \\ Central Ukrainian National Technical University \\ Kropyvnytskyi, Ukraine \\ matsuyan@ukr.net
}

\author{
Vasyl Kondratets \\ Department of Automation of Production Processes \\ Central Ukrainian National Technical University \\ Kropyvnytskyi, Ukraine \\ kondratetsva@gmail.com
}

\author{
Anastasiia Abashina \\ Department of Cyber Security and Software \\ Central Ukrainian National Technical University \\ Kropyvnytskyi, Ukraine \\ garmonia30@gmail.com
}

\begin{abstract}
Factors are identified whose role in increasing the productivity of ball mills is not fully disclosed. The criterion of optimality in the task of increasing the energy efficiency of ore grinding by ball mills and the influence of these factors on its value. Ways to improve the energy efficiency of ore grinding are proposed..
\end{abstract}

Keywords- ball mills; grinding; energy efficiency; optimization; factors

\section{INTRODUCTION}

The raw material base of the ferrous metallurgy of Ukraine is iron ore concentrate obtained by beneficiation of poor iron ores. Significant cost overruns of electricity, steel balls and lining during the ore preparation process, especially in the first stage of grinding, increase the cost of concentrate and reduce the competitiveness of both the concentrate itself in its direct sale and domestic iron and steel products on the international market. This is primarily due to the low value of the mechanical efficiency of the ball mill during the formation of a new surface, not exceeding 1\% [1]. One of the ways to improve the situation is to increase the energy efficiency of ore grinding by ball mills, which is hampered by the lack of alternative technological units and effective measures to modernize existing equipment.

This problem is reflected in government documents and is part of the scientific topics of a number of specialized organizations, in particular, the Central Ukrainian National Technical University, which is developing the topic: "Optimization of the performance of ball mills in ore and finished product with minimal energy and material overhead" (0115U003942). Since this publication is aimed at solving one of the problems mentioned, its topic is relevant.

\section{ANALYSIS OF LATEST RESEARCHES AND PUBLICATIONS}

Scientists and practitioners have been engaged in improving the energy characteristics of a ball mill for a long time, but the problem remains unsolved. At the end of the 20th century and the beginning of the 21 st century, research on the creation of alternative technical equipment for a ball mill began, but analysis shows that in the near future they will not be created. As a means of increasing the energy efficiency of ore grinding consider rational selection of technical and technological parameters of grinding departments for each specific case, as well as the introduction of preliminary enrichment. Modernization of ball mills aimed at shear ore destruction was not developed due to the low reliability of the contact with the ball loading elements protruding in the middle of the drum. The same fate befell the device based on the effect of self-excitation of load pulsations under constant modes of movement of the mechanical system of the mill. Recent studies are mainly devoted to the analysis of the reasons for the low energy efficiency of the destruction of mineral raw materials [2] and the problems of reducing energy intensity and increasing the efficiency of ore preparation processes [3]. These works mainly reveal the causes and problems of low energy efficiency of ore grinding, and specific solutions are not proposed. Therefore, these paths need clarification and they relate to modern ball mills.

\section{FORMULATION OF RESEARCH OBJECTIVES}

The purpose of this publication is to identify factors whose role in increasing the performance of a ball mill is not fully disclosed, to determine the optimality criterion and the influence of these factors on the optimality criterion when fully implemented, and to develop possible ways to improve the energy efficiency of ore preparation in the first stages of grinding. 


\section{Modeling, control and information technologies -2020}

\section{STATEMENT OF THE MAIN MATERIAL}

Having systematically examined the factors that determine the productivity of a ball mill, we conclude that the role of nine quite important of them, which are presented in Fig. 1, remains fully disclosed.. The analysis associated with identifying the possibility of increasing the productivity of a ball mill must be subjected to all the factors shown in Fig.1. It is easy to establish that they are simultaneously attached to the technological unit, however, some affect the entire object, others only its part. Despite this, when studying the influence of the design of a ball mill, its size, ore load, efficiency of the classifying apparatus on productivity, it is necessary to consider the whole technological unit as a whole. In the process of studying the influence of other factors on the productivity of the mill, it is advisable to decompose the object and consider their role separately, followed by a generalization of the result. When decomposing a ball mill, it is necessary to separate and study separate independent subsystems: lining, grinding medium, ore crushability, pulp liquefaction (viscosity). In this case, one independent subsystem of the grinding medium will include the actions of factors - the characteristic size of the grinding bodies, the correctness of their shape, density and hardness.

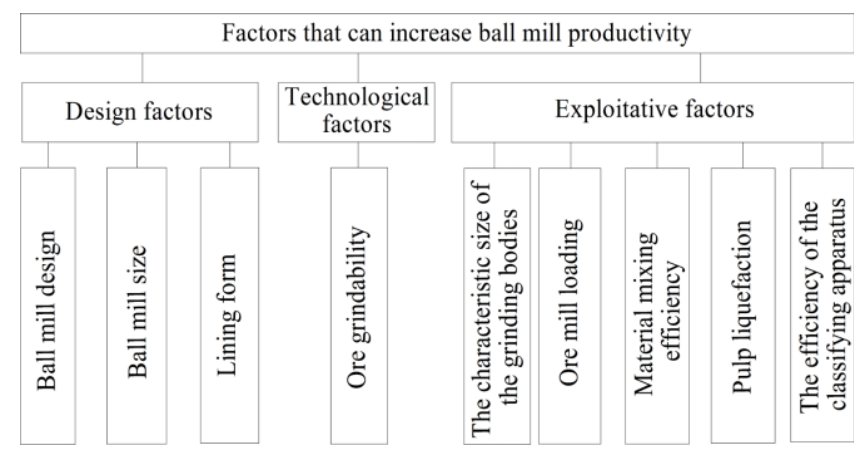

Figure 1. Factors whose role in improving ball mill performance is not fully disclosed

The analysis shows that the effect of the studied factors on the energy efficiency of ore grinding in a ball mill cannot be expressed in the same units of measurement, since there is no specific data on their effect on the operation of the grinding unit. Therefore, analyzing the effect of a specific factor on the operation of a ball mill, we bring its significant positive impact. If it is, for example, an increase in productivity or a decrease in energy consumption, we set a conditional assessment of its impact. In this case, it is necessary to take into account the degree of influence of a particular factor on the effect created. As early as the beginning of the 60s of the last century, it was established that automatic regulation of the ore grinding process allows increasing mill productivity by $5 . . .10 \%$ [4]. Since a $5 \%$ increase in productivity is a significant quantity, this level can be taken as a unit of reference for the positive effect of a specific factor. If, for example, an increase in productivity is $10 \%$, then two units must be taken into account, etc. As analysis shows, with this approach it is possible to combine the action of all factors on the result of a ball mill as a whole and obtain the resulting effect. This can be achieved by solving the optimal problem.
The goal of optimization in this problem is to obtain a resulting estimate of the increase in energy efficiency of a ball mill during ore grinding in the first stage. It is clear that this task relates to static optimization.

The object of optimization here is the process of increasing the energy efficiency of ore grinding by a ball mill. The optimization object provides for the selection of four groups of parameters - input, control, disturbing and output. These parameters should be considered either to a ball mill as a whole or to its individual independent subsystems. The input parameters in this process include the consumption of material in a ball mill, the electricity supplied to the technological unit. The initial parameter here will be the energy efficiency of grinding as a parameter of the state of the object. Since it is not possible to determine it in these studies, it is necessary to consider as the initial parameters an increase in productivity, a decrease in energy consumption, and possibly some others that provide a positive effect. Disturbing parameters randomly change their values over time. They are usually inaccessible for measurement and tasks known in content. Control parameters are those that can be directly influenced in accordance with certain requirements, allowing you to control the process. According to the meaning of this task, the controlling parameters must include the factors affecting the ball mill, or their individual components. The mathematical models of this optimization object are dependencies that relate to the theory of ball mills. In mathematical models, the idealized productivity of a ball mill was considered in certain conditions, that is, the one that the unit develops during its operation. However, it must be corrected, taking into account the time for equipment downtime during scheduled preventive repairs, for the replacement of the lining and ball loading, and the failure of technological units. Actual performance can be determined according to the formula

$$
Q_{\phi}=Q \cdot \frac{\left(n_{p}-n_{N}\right)}{n_{p}},
$$

where $Q$-productivity mill;

$n_{p}$ - number of working days per year;

$n_{N}-$ the number of days of downtime of technological equipment per year.

This will take into account the reliability of technological equipment, the effectiveness of its repair and maintenance, which affects the annual performance of the processing plant.

These mathematical models of the optimization object are supplemented by the relations of the output and control parameters, which are established experimentally.

The main limitations here are

$$
Q>Q_{N} \text { at } N \leq N_{\mathrm{N}} \text { or } Q=Q_{N} \text { at } N<N_{\mathrm{N}},
$$

where $Q, N$ - correspondingly achieved productivity with useful power;

$Q_{N}, N_{N}$ - productivity and useful power of the normative grinding process wasted (before optimization).

To solve the problem, it is necessary to determine the optimality criterion. As an optimality criterion, the requirement 


\section{Modeling, control and information technoloaies -2020}

to achieve the highest value of the conditional assessment from the influence of individual factors can be put forward. At the same time, it is convenient to take " 1 " for counting the achieved significant positive effect when exposed to a specific factor, that is, $J_{i}=1$.

Based on the considered and taking into account the number of variables, types of mathematical models and constraints, we conclude that the dynamic programming method is suitable for solving this optimization problem, since it is an effective means of solving optimization problems of discrete multi-stage processes for which the general optimality criterion is described by the additive function of the criteria optimality of individual stages. Here we distinguish nine stages of optimization, meaning under the stage one of the influential factors - the design of the ball mill, the size of the ball mill, etc.

The dynamic programming method is actually an algorithm for determining the optimal control strategy at all stages of the process. The control law at each stage is usually found by solving particular optimization problems sequentially for all stages of the process using other research methods. In most practical problems, the final result is obtained only in numerical form. We use the Gauss-Seidel method. In this method, all independent variables are changed in turn so that for each of them the highest value of the optimality criterion is reached. In this case, the sequence of variation of independent variables can be set arbitrarily. The resulting optimality criterion will be equal to the sum of the optimality criteria obtained in each stage. In this problem, the input of the first stage corresponds to the zero value of the optimality criterion $J=0$. It is possible to start optimization here with any factor.

Using a fairly wide range of domestic and foreign literary sources, through analysis, optimality criteria were established at each stage of optimization, which were devoted to a separate factor.

As a result of the studies, it was found that in all areas of a possible improvement in the energy efficiency of ore grinding in ball mills, a positive result was obtained. In individual stages of optimization, various criteria have been obtained - from 1 to 9. Most factors provide an optimality criterion at the unit level, however, by choosing the design or size of a ball mill, it can be increased immediately by 4 units. When properly selected, the grinding media provides the value of the optimality criterion at level 9. The rubber lining, when it has stable results in the first grinding stage, can provide the value of the optimality criterion at level 7. A graphical interpretation of the resulting optimality criterion for optimizing the energy efficiency of ore grinding in ball mills with the full realization of the influence of all factors is shown in Fig.2. As can be seen from Fig.2, before optimization, the criterion is zero, then it increases from stage to stage, reaching the highest value of 29 . The order of implementation of the optimization stages does not affect the final result. The final optimization result is significant, however, it is necessary to consider in more detail ways to achieve increased efficiency of the ball mill.

Figure 2. The influence of factors on the criterion of optimality in their full implementation

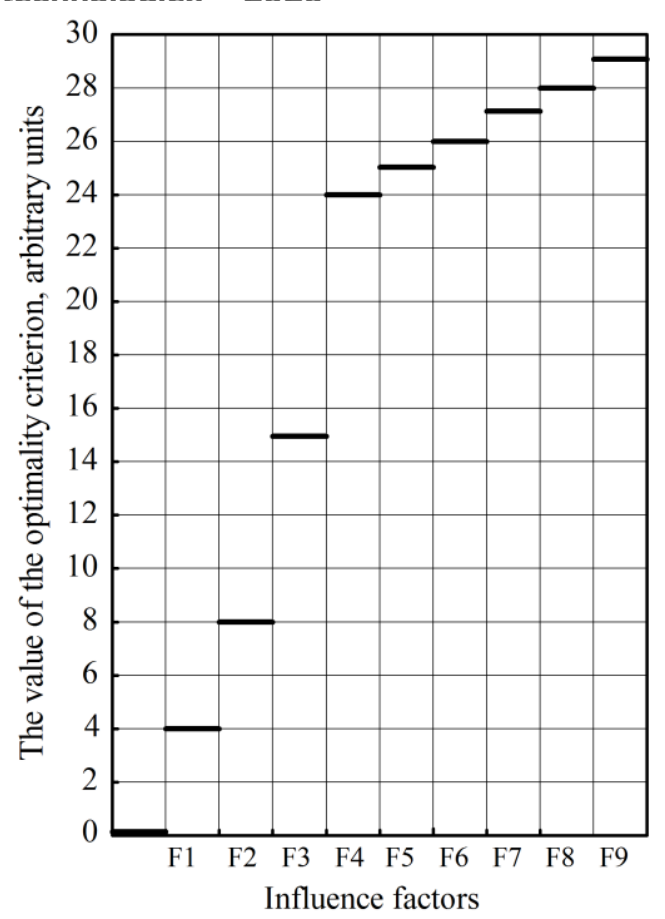

The most likely options are presented in Fig.3. Here we consider possible options for improving the performance of a ball mill in various conditions of the enterprise or the wishes and capabilities of the management team. As can be seen from Fig.3, according to all the options presented, it is possible to achieve a significant improvement in the operation of a ball mill. The realization of benefits, even from the influence of one of the factors, is not excluded. Since the condition " 1 " was initially introduced to consider the improvement of the result from the influence of the factor by $5 \%$, then according to the optimality criterion, we can evaluate the influence of one or more factors on increasing the efficiency of the ball mill. For example, an option where the optimality criterion is $J=15$, the relative change in the indicator will be $0.05 \times 15=0.75$. This means that the efficiency of the ball mill can improve 1.75 times. As you can see, the efficiency of the ball mill can significantly improve - up to 2.5 times compared with the existing version. However, only the technical side of the issue regarding the technological unit is considered here. To realize these opportunities, it is necessary to incur some time and financial costs. Firstly, many of the above require automatic control. Secondly, in some cases it is necessary to upgrade or purchase new equipment. Thirdly, and most importantly, in order to achieve the tasks set, it is necessary in many cases to change the psychology of attitude to work, to increase professionalism and responsibility for the performance of official duties. It is necessary to carefully comply with the instructive requirements for the process and equipment, including strict quality control of the lining, balls, regulations and quality of repair work, etc. The same attention should be paid to raw materials for processing, since it is often more costly in comparison with equipment and materials used in processing. In addition, raw materials should not go beyond the quality attributed to the process. To successfully solve the tasks, it is necessary to combine the efforts of all participants in this rather complicated process. 


\section{Modeling, control and information technologies -2020}

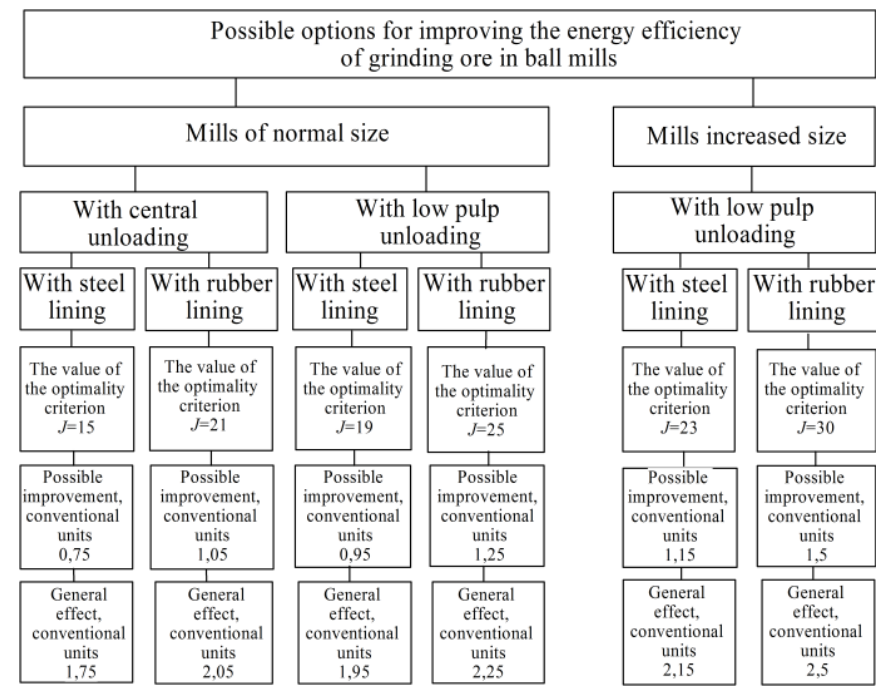

Figure 3. Possible ways to implement improved energy efficiency of ore grinding in ball mills

It is also necessary to bear in mind that with an increase in the unit productivity of ball mills, a deterioration in energy transfer indicators is clearly visible. The increase in energy efficiency is observed for ball mills with a volume of up to $60 \mathrm{~m}^{3}$, then the energy efficiency increases slowly or even stabilizes. The limit of this indicator is $8 \ldots 10 \mathrm{~kW} / \mathrm{t}$. Prof. S.F. Shinkarenko notes that for ball mills, with an increase in diameter, capital and reduced costs increase. In each case, there is a mill size, the excess of which reduces the grinding efficiency. A little later in [5] it is noted: "with an increase in the size of the mill more than certain values, the grinding efficiency in them decreases; changing the diameter, length and frequency of rotation of the drum to varying degrees affects the performance and specific consumption of electricity". It is further noted that a higher productivity gain per cubic meter of mill volume increase at lower specific energy costs corresponds to the option with increasing drum length. So, there is an improvement, but it is necessary to make clarifications in each specific situation.

\section{CONCLUSIONS AND PROSPECTS FOR FURTHER RESEARCH}

Thus, an analysis of domestic and foreign practical experience of ore preparation was carried out, factors that could affect the improvement of the energy efficiency of ore grinding by ball mills were identified. Using dynamic programming method, the energy efficiency of ore grinding by ball mills was optimized, where nine stages were considered.
At each stage of optimization, by analyzing the processes, the absolute level of the optimality criterion was established with a value of " 1 ", if the indicator improved by $5 \%$, that is, with each $5 \%$ increase in the indicator, it was set to " 1 ". In all stages, the optimality criterion was at least 1 , the highest value was obtained at level 9, and the resulting optimality criterion, equal to the sum of the partial, was 29.

According to the data of the optimization process, ways to implement the improvement of the energy efficiency of ore grinding in ball mills in the form of six branches are proposed, which can provide a result based on the wishes and capabilities of the enterprise. The practical implementation of indicators in a separate optimization stage is not ruled out, and there can be any sequence of problem solving. Improving the performance of a ball mill can reach up to 2.5 times in comparison with the existing version of its operation. The implementation of optimal options for improving ore grinding requires time and money, as well as automation of a number of processes, which negates the influence of the human factor on the final result. Raising the work of grinding aggregates to a new level also requires a change in the psychology of workers, increasing professionalism, the strict implementation of official instructions, etc., i.e. the transfer of labor organization to a new qualitative level and the unification of efforts of all participants in this process.

The prospect of further developments in this direction is the creation of methods for implementing the influence of individual factors on improving the energy efficiency of ore grinding by ball mills from the initial state to a level of 2.5 times.

\section{REFERENCES}

[1] Yu.V. Naumenko Basics of the theory of modes of operation of drum mills. Rivne: SPD Zelent, 2009. 282 p.

[2] Hopunov E.A. Analysis of the reasons for the low energy efficiency of the destruction of mineral raw materials. Modern equipment and technology. 2014. No. 10. pp. 42-51.

[3] Malyarov P.V. The problems of reducing energy intensity and improving the efficiency of ore preparation processes. Modern processes of complex and deep processing of refractory mineral raw materials (Plaksinsky readings 2015): materials int. conference (Irkutsk, September 21-25, 2015). Irkutsk, 2015. pp.65-70.

[4] Bozhko M.P., Margulis V.S. The mill operator. Moscow: Gostekhnauchizdat lit. in mining, $1962.100 \mathrm{p}$.

[5] Chertkov Yu.A., Gezagt Sh., Ganbaatar Z., Vatagin N.A., Panteleev V.A., Tukharinov L. Yu., Nikurashin V.V., Turiansky Yu. D., Zakharchuk V.N. Modernization ball mills at the enrichment plant SP "ERDENET". Mountain Journal. 2004. No. 8. pp. 58-62. 